\title{
PENGARUH PROMOSI DAN KUALITAS LAYANAN TERHADAP KEPUTUSAN PEMBELIAN MAHASISWA MEMILIH PROGRAM UNIPREP BUMI SERPONG DAMAI DI TANGERANG SELATAN
}

\author{
Reza Suriansha \\ STIE Unisadhuguna, Jakarta, Indonesia \\ Email : reza@ubs-usg.ac.id
}

\begin{abstract}
Abstrak
Pendahuluan : Promosi menjadi faktor yang dianggap mampu mempengaruhi keputusan pembelian pada barang/jasa, yang merupakan aktivitas pemasaran yang berusaha menyebarkan informasi, mempengaruhi atau membujuk, dan atau meningkatkan pasar sasaran atas perusahaan dan produknya agar bersedia menerima, membeli, dan loyal pada produk yang ditawarkan perusahaan bersangktuan.

Tujuan : Penelitian ini bertujuan untuk mengetahui apakah ada pengaruh promosi dan kualitas pelayanan terhadap keputusan mahasiswa di kampus UNIPREP BSD. Metode : Penelitian ini dilakukan pada bulan Mei 2019 melalui penyebaran kuisioner (research questioner). Populasi dalam penelitian ini adalah mahasiswa aktif uniprep selama penelitian. Pengambilan sampel menggunakan teknik simple random sampling. Data penelitian diperoleh melalui angket tentang promosi kualitas pelayanan dan keputusan mahasiswa kepada 40 responden. Metode pengujian instrumen yang digunakan adalah uji validitas dan uji reliabilitas. Teknik analisis data yang digunakan adalah teknik deskriptif kuantitatif, analisis regresi linier berganda, uji t, dan uji F.

Hasil : Hasil penelitian menunjukkan bahwa dalam promosi berpengaruh signifikan terhadap keputusan mahasiswa, sedangkan kualitas pelayanan tidak berpengaruh terhadap keputusan mahasiswa memilih UNIPREP BSD pada alpha 5\%. Secara bersamaan, promosi dan kualitas layanan memberikan kontribusi yang signifikan terhadap keputusan mahasiswa untuk memilih UNIPREP BSD.

Kesimpulan : Semakin bagus promosi yang digunakan dalam sebuah iklan maka akan meningkatkan keputusan mahasiswa memilih program UNIPREP BSD, begitu pula sebaliknya. Sedangkan kualitas layanan tidak berpengaruh terhadap keputusan mahasiswa memilih program UNIPREP BSD pada tingkat kesalahan 5\%. Secara simultan, promosi dan kualitas layanan berpengaruh terhadap keputusan mahasiswa memilih program UNIPREP BSD.
\end{abstract}

Kata Kunci : Promosi; Kualitas Pelayanan; Keputusan Siswa.

\section{Abstract}

Introduction : Promotion becomes a factor that is considered able to influence purchasing decisions on goods / services, which is a marketing activity that seeks to disseminate information, influence or persuade, and or increase the target market of the company and its products in order to be willing to accept, buy, and be loyal to the products offered by the company.

Purpose : This research aims to find out if there is an influence of promotion and quality of service on student decisions at uniprep bsd campus. 


\begin{abstract}
Method: This research was conducted in May 2019 through the dissemination of questionnaires (research questioner). The population in the study was uniprep active students during the study. Sampling using simple random sampling techniques. The research data was obtained through questionnaires on the promotion of quality of service and student decisions to 40 respondents. The instrument testing methods used are validity tests and reliability tests. The data analysis techniques used are quantitative descriptive techniques, multiple linear regression analysis, $t$ test, and $F$ test.

Results : The results showed that in promotion has a significant effect on student decisions, while the quality of service has no effect on the decision of students to choose UNIPREP BSD at alpha 5\%. Simultaneously, promotion and quality of service contributed significantly to students' decision to choose UNIPREP BSD.

Conclusion : The better the promotion used in an advertisement, it will increase the decision of students to choose the UNIPREP BSD program, and vice versa. While the quality of service has no effect on the decision of students to choose the UNIPREP BSD program at a 5\% error rate. Simultaneously, promotion and quality of service affect the decision of students to choose the UNIPREP BSD program.
\end{abstract}

Keywords: promotion; quality of service; student decisions.

\title{
Pendahuluan
}

Dewasa ini lazim diterima bahwa pendidikan juga termasuk dalam kategori bisnis jasa. Calon mahasiswa akan dihadapkan pada beragam pilihan perguruan tinggi, jenjang pendidikannya, hingga pilihan berbagai macam program studi. Selain itu, juga akan dihadapkan pada begitu banyaknya pertimbangan yang harus dipikirkan. Menurut (Lupiyoadi \& Hamdani, 2014) mengemukakan ada 5 dimensi makna perguruan tinggi atau institusi di bidang pendidikan, yaitu: dimensi keilmuan (ilmu dan teknologi), dimensi pendidikan (pendidikan tinggi), dimensi sosial (kehidupan masyarakat), dimensi korporasi (satuan pendidikan dan penyelenggaraan) dan dimensi etis.

Berbagai strategi diterapkan lembaga-lembaga pendidikan agar dapat bertahan di tengah ketatnya persaingan bisnis (Kholik \& Laeli, 2020). Hal ini didorong oleh adanya tuntunan bagi lembaga-lembaga pendidikan tersebut untuk senantiasa memiliki keunggulan di tengah pasar yang kompetitif. Strategi yang umum digunakan antara lain adalah strategi promosi pemasaran. Strategi ini harus sesuai dengan situasi dan kondisi perusahaan, ketersediaan dana serta manfaat-manfaat yang dapat diperoleh melalui kegiatan-kegiatan promosi yang dijalankan oleh perusahaan.

Keputusan penggunaan jasa menurut (Khotler \& Amstrong, 2018), adalah proses pengintegrasian yang mengkombinasi sikap pengetahuan untuk mengevaluasi dua atau lebih perilaku alternatif, dan memilih salah satu diantaranya. Menurut (Kotler \& Keller, 2021) tahap evaluasi alternatif dan keputusan pembelian terdapat minat membeli awal, yang mengukur kecenderungan pelanggan untuk melakukan suatu tindakan tertentu terhadap produk secara keseluruhan. Proses yagn dilakukan dalam hal keputusan pembelian adalah diawali dengan pengenalan masalah, pencarian informasi, evaluasi alternatif, keputusan pembelian, dan perilaku setelah pembelian. 
Promosi menjadi faktor yang dianggap mampu mempengaruhi keputusan pembelian pada barang/jasa, yang merupakan aktivitas pemasaran yang berusaha menyebarkan informasi, mempengaruhi atau membujuk, dan atau meningkatkan pasar sasaran atas perusahaan dan produknya agar bersedia menerima, membeli, dan loyal pada produk yang ditawarkan perusahaan bersangktuan (Alma, 2018). Promosi yang baik adalah promosi yang mampu memberikan informasi mengenai produk serta manfaat dari produk bagi konsumen, membujuk untuk mengikuti pesan yang disampaikan dalam promosi, serta menciptakan kesan positif di benak konsumen.

Kualitas pelayanan merupakan salah satu faktor yang dianggap mampu mempengaruhi minat penggunaan jasa. Menurut (Tjiptono, 2015) kualitas layanan (service quality) sebagai ukuran seberapa bagus tingkat layanan yang diberikan mampu sesuai dengan ekspektasi pelanggan. Persaingan pasar yang semakin ketat, membuat banyak perusahaan membicarakan tentang kualitas, dimana menurut mereka kualitas layanan mereka adalah yang terbaik (Priyatna, 2015). Selain itu kepeduliaan terhadap kualitas layanan, menjadi alasan untuk mencari hati konsumen. Di lain pihak, konsumen akan merasa sangat puas dan senang jika jasa yang mereka beli sesuai dengan ekspetasi mereka, sesuai dengan keinginan mereka, dan sesuai dengan apa yang telah digembargemborkan. Pada prinsipnya, kualitas pelayanan berfokus pada upaya pemenuhan kebutuhan dan keinginan pelanggan, serta ketepatan penyampaiannya untuk mengimbangi harapan pelanggan. Menurut (Sondakh, 2015) terdapat lima dimensi kualitas pelayanan sesuai urutan derajat kepentingannya yakni Keandalan (realibility), Ketanggapan (Responsiveness), Jaminan dan Kepastian (Assurance), Empati (Empathy) dan Bukti Fisik (Tangibles).

Uniprep adalah UNSW Foundation Studies yang sudah berlangsung di Jakarta sejak tahun 1994. Kurikulum, dan standard yang dijalankan di Uniprep sama dengan UNSW Foundation Studies yang ada di Australia. Materi pelajaran dan bahan ujian semester yang dipergunakan pun dikirim langsung dari UNSW Foundation Studies, Australia.Program ini ditujukkan bagi siswa yang duduk di Year 10 atau Year 11, namun juga tidak menutup kemungkinan bagi calon-calon mahasiswa yang berasal dari SMA 2 atau SMA 3.

Uniprep BSD berusaha untuk selalu menghasilkan output dengan kompetensi yang baik dan sesuai dengan standar mutu yang baik dengan memberikan Pendidikan yang berkualitas, fasilitas yang memadai, kurikulum yang sesuai dengan kondisi perkembangan jaman. Hal inilah yang menjadikan citra Uniprep BSD cukup baik. Banyak strategi yang dilakukan Uniprep untuk dapat meningkatkan jumlah mahasiswa baru, antara lain dengan mengikuti pameran, pelatihan ke sekolahsekolah terkait, pemasangan iklan di berbagai media cetak dan elektronik, publikasi karya mahasiswa, hingga penawaran beasiswa yang menarik, namun kondisi yang terjadi tiga tahun terakhir adalah peningkatan jumlah mahasiswa baru tidak signifikan dan tidak konsisten, dengan jumlah peningkatan jika dirata-rata kurang dari 30\%. Tidak konsistennya jumlah mahasiswa yang mendaftar, mengindikasikan bahwa terdapat masalah dalam pengambilan keputusan yang dilakukan oleh calon mahasiswa untuk melanjutkan pendidikannya di Uniprep BSD. Berdasarkan konsep yang ada suatu masalah timbul apabila keadaan ideal tidak sesuai dengan kenyataan yang ada. Banyak hal yang menjadi pertimbangan mahasiswa dalam 
memillih perguruan tinggi, antara lain citra dari perguruan tinggi, promosi, biaya studi, fasilitas dan kualitas pelayanan.

\section{Metode Penelitian}

Populasi dalam penelitian ini adalah mahasiswa yang pernah atau masih menempuh pendidikan di Uniprep BSD antara tahun 2018-2019 dimana jumlahnya adalah 44 orang. Pada Metode Penelitian, Teknik sampling yang digunakan adalah simple random sampling (Arieska \& Herdiani, 2018).

Teknik pengumpulan data dalam penelitian ini dilakukan dengan 2 (dua) cara, yaitu dengan menyebarkan kuesioner (daftar pertanyaan) kepada para mahasiswa/I Uniprep sesuai dengan masa penelitian dengan harapan dapat memberikan respon terhadap daftar pertanyaan tersebut. Kuesioner disusun menggunakan skala likert. Pengumpulan data berikutnya dilakukan mengadakan studi penelaahan terhadap bukubuku, litertur-literatur, catatan-catatan, dan laporan-laporan yang ada hubungannya dengan masalah yang dipecahkan (Cresswell, 2017).

Setelah data-data yang diperlukan didapat, langkah selanjutnya adalah dengan melakukan uji instrumen. Dalam langkah ini dilakukan dalam 2 (dua) tahap pengujian, yaitu uji validitas dan uji reliabilitas. Untuk menguji validitas kuesioner digunakan rumus korelasi Product Moment Pearson. Sedangkan uji reliabilitas menggunakan alat ukur dengan rumus Alpha Cronbach (Sugiyono, 2016). Dengan Interpretasi koefisien Korelasi r sebagai berikut (Sugiyono, 2016).

Tabel 1

Interpretasi Koefisien Korelasi Nilai $\mathbf{r}$

\begin{tabular}{ll}
\hline Interval Koefisien & Tingkat Hubungan \\
\hline $0,80-1,000$ & Sangat Kuat \\
$0,60-0,799$ & Kuat \\
$0,40-0.599$ & Cukup Kuat \\
$0,20-0,399$ & Rendah \\
$0,00-0,199$ & Sangat Rendah \\
\hline
\end{tabular}

Uji asumsi klasik dalam penelitian ini di lakukan dalam 3 (tiga) pengujian, yaitu: normality test, multicoliinierity test, dan heteroscedasticity test (Arikunto, 2016). Normality test menggunakan metode Kolmogorov smirnov. Multicoliinierity test dilakukan dengan cara menghitung nilai Variance Inflation Factor (VIF) terhadap semua variabel bebasnya. Terjadi multikolinearitas jika nilai VIF $>10,00$. Jika nilai VIF $<$ 10,00 korelasi antar variabel bebasnya masih dapat ditolerir (Sugiyono, 2016) Sedangkan uji heteroskedastisitas menggunakan metode Glejser (Palupi, 2020).

Pengujian berikutnya adalah pengujian parameter, meliputi uji parameter individual (uji statistik t) bertujuan untuk mengukur seberapa jauh pengaruh satu variabel independen secara individual dalam menerangkan variasi variabel dependen dan uji parameter secara simultan (Saputri \& Yuyetta, 2012). Dan yang terakhir adalah pengujian best of fit model 


\section{Hasil dan Pembahasan}

Penelitian yang menggunakan kuesioner / angket, terlebih dahulu harus dilakukan uji instrumen, yang terdiri dari:

1. Uji Validitas

Hasil uji validitas variabel independen penelitian dapat dilihat pada Tabel 2

Tabel 2

Hasil Uji Validitas Variabel-variabel Penelitian

\begin{tabular}{|c|c|c|c|c|c|c|c|c|}
\hline \multicolumn{3}{|c|}{ Promosi $\left(\mathrm{X}_{1}\right)$} & \multicolumn{3}{|c|}{ Kualitas Layanan $\left(\mathrm{X}_{2}\right)$} & \multicolumn{3}{|c|}{ Keputusan Pembelian $\left(\mathrm{X}_{3}\right)$} \\
\hline $\begin{array}{l}\text { No. } \\
\text { Butter }\end{array}$ & $\mathbf{r}_{\text {hitung }}$ & Keterangan & $\begin{array}{c}\text { No. } \\
\text { Butter }\end{array}$ & $\mathbf{r}_{\text {hitung }}$ & Keterangan & $\begin{array}{c}\text { No. } \\
\text { Butter }\end{array}$ & $\mathbf{r}_{\text {hitung }}$ & Keterangan \\
\hline 1 & 0,65 & Valid & 1 & 0,87 & Valid & 1 & 0,94 & Valid \\
\hline 2 & 0,70 & Valid & 2 & 0,49 & Valid & 2 & 0,86 & Valid \\
\hline 3 & 0,65 & Valid & 3 & 0,49 & Valid & 3 & 0,94 & Valid \\
\hline 4 & 0,64 & Valid & 4 & 0,88 & Valid & 4 & 0,76 & Valid \\
\hline 5 & 0,74 & Valid & 5 & 0,87 & Valid & 5 & 0,92 & Valid \\
\hline 6 & 0,49 & Valid & 6 & 0,78 & Valid & 6 & 0,53 & Valid \\
\hline 7 & 0,74 & Valid & 7 & 0,60 & Valid & 7 & 0,86 & Valid \\
\hline 8 & 0,75 & Valid & 8 & 0,92 & Valid & 8 & 0,86 & Valid \\
\hline 9 & 0,77 & Valid & 9 & 0,63 & Valid & 9 & 0,86 & Valid \\
\hline 10 & 0,71 & Valid & 10 & 0,58 & Valid & 10 & 0,92 & Valid \\
\hline
\end{tabular}

Dari Tabel 2 di atas dapat dilihat bahwa semua item pernyataan dari masingmasing variable penelitian valid.

2. Uji Reliability

Hasil penelitian menunjukan bahwa semua variabel penelitian reliabel. Hal ini ditunjukkan pada Tabel 3

Tabel 3

Hasil Uji Reliabilitas Variabel-variabel Penelitian

\begin{tabular}{llll}
\hline \multicolumn{1}{c}{$\begin{array}{c}\text { Varibel } \\
\text { Instrumen }\end{array}$} & $\begin{array}{c}\text { Cronbach's } \\
\text { Alpha }\end{array}$ & Keterangan & Kategorisasi \\
\hline $\begin{array}{l}\text { Promosi } \\
\left(\mathrm{X}_{1}\right)\end{array}$ & 0,631 & Reliabel & Tinggi \\
\hline $\begin{array}{l}\text { Kualitas } \\
\text { layanan } \\
\left(\mathrm{X}_{2}\right)\end{array}$ & 0,774 & Reliabel & $\begin{array}{l}\text { Sangat } \\
\text { Tinggi }\end{array}$ \\
\hline $\begin{array}{l}\text { Keputusan } \\
(\mathrm{Y})\end{array}$ & 0,829 & Reliabel & Tinggi \\
\hline
\end{tabular}

Sumber: Data diolah

3. Uji Asumsi Klasik

Model regresi yang baik, harus memenuhi asumsi BLUE, yaitu Best LinearUnbiased Estimator.

a. Uji Normality

Uji asumsi normalitas pada penelitian ini dilakukan dengan mengunakan uji Kolmogorov Smirnov. Kriteria penerimaan normalitas adalah jika nilai signifikansi hasil perhitungan lebih besar dari $\alpha=0,05$ maka distribusinya 
dinyatakan normal, sebaliknya jika lebih kecil dari $\alpha=0,05$ maka distribusi dinyatakan tidak normal (Priyanto \& Budiwiyono, 2019). Hasil penghitungan untuk semua variabel disajikan dalam Tabel 4

Tabel 4

Hasil Uji Normalitas Menggunakan Metode Kolmogorov-Smirnov

\begin{tabular}{lcl}
\hline \multicolumn{1}{c}{ Variabel } & Sig. & Kesimpulan \\
\hline Promosi $\left(\mathrm{X}_{1}\right)$ & 0,387 & Normal \\
\hline Kualitas layanan $\left(\mathrm{X}_{2}\right)$ & 0.213 & Normal \\
\hline $\begin{array}{l}\text { Keputusan mahasiswa } \\
\left(\mathrm{X}_{3)}\right.\end{array}$ & 0,097 & Normal \\
\hline
\end{tabular}

Berdasarkan hasil pengujian normalitas pada Table 4 di atas, dapat dilihat bahwa nilai signifikansi tiap-tiap variabel lebih besar dari 0,05. Dengan demikian, dapat disimpulkan bahwa ketiga variabel penelitian ini berdistribusi normal.

b. Uji Linearity

Uji linearitas dilakukan untuk mengetahui apakah variabel dependen (X) dengan variabel dependen (Y) mempunyai hubungan yang linear. Pengujian linearitas untuk melihat spesifikasi model yang digunakan sudah benar, yang berarti model yang didapat adalah model linear karena pengujian hipotesis dilakukan dengan analisis regresi linear berganda.

Tabel 5

Hasil Uji Linearitas Varibel-variabel Penelitian

\begin{tabular}{lll}
\hline Variabel & $\begin{array}{c}\text { Sig. Deviation } \\
\text { from linearity }\end{array}$ & Kesimpulan \\
\hline $\mathrm{X}_{1} \rightarrow \mathrm{Y}$ & 0,742 & Linear \\
\hline $\mathrm{X}_{2} \rightarrow \mathrm{Y}$ & 0,849 & Linear \\
\hline \multicolumn{3}{c}{ Sumber: Data diolah }
\end{tabular}

Berdasarkan hasil pengujian pada Tabel 5 di atas, terlihat bahwa nilai signifikan antara variabel promosi (X1) terhadap keputusan mahasiswa (Y), dan kualitas layanan (X2) terhadap keputusan pembelian (Y) masing-masing sebesar 0,742 dan 0,849 . Hasil tersebut menunjukkan signifikan. Nilai signifikansi untuk masing-masing variabel penelitian lebih besar dari 0,05 sehingga dapat disimpulkan bahwa hubungan antara masing-masing variabel independen dengan variabel dependen adalah berbentuk linear.

\section{c. Uji Multikolinearitas}

Uji multikolinearitas bertujuan untuk mengetahui apakah terdapat hubungan yang kuat antar variabel independen. Di dalam penelitian ini uji multikolinearitas menggunakan nilai VIF dan tolerance. Hasil yang didapat disajikan pada Tabel 6 
Tabel 6

Hasil Uji Multikolinearitas

\begin{tabular}{ccccc}
\hline No & Variabel & Tolerance & VIF & Keterangan \\
\hline 1 & $\begin{array}{c}\text { Promosi } \\
\left(\mathrm{X}_{1}\right)\end{array}$ & 0,988 & 1,012 & $\begin{array}{c}\text { Bebas } \\
\text { multikolinearitas }\end{array}$ \\
\hline 2 & $\begin{array}{c}\text { Kualitas } \\
\text { Layanan } \\
\left(\mathrm{X}_{2}\right)\end{array}$ & 0,988 & 1,012 & $\begin{array}{c}\text { Bebas } \\
\text { multikolinearitas }\end{array}$ \\
\hline \multicolumn{5}{c}{ Sumber: Data Diolah }
\end{tabular}

Berdasarkan Tabel 6 di atas yang menunjukkan nilai tolerance untuk semua variabel independen lebih besar dari 0,1 dan nilai VIF kurang dari 10, maka dapat disimpulkan bahwa variabel independen bebas multikolinearitas.

d. Uji Heterokedastisitas

Heteroskedastisitas adalah varian residual dalam model tidak homogen. Uji untuk mendeteksi adanya gejala heteroskedastisitas dilakukan dengan dengan uji Gletser. Hasil uji heteroskedastisitas dapat dilihat pada Table 7

Tabel 7

Hasil Uji Heteroskedastisitas

\begin{tabular}{lcc}
\hline Variabel & Sig. & Kesimpulan \\
\hline $\mathrm{X}_{1} \rightarrow \mathrm{Y}$ & 0,554 & Bebas heteroskedastisitas \\
\hline $\mathrm{X}_{2} \rightarrow \mathrm{Y}$ & 0,735 & Bebas heteroskedastisitas \\
\hline \multicolumn{3}{c}{ Data diolah }
\end{tabular}

Dari tabel 7 bahwa nilai signifikansi untuk semua variabel independen terhadap dependen lebih besar dari 0,05, sehingga disimpulkan variabel penelitian bebas dari gejala heteroskedastisitas.

e. Uji Individual dan Uji Simultan

Pengujian selanjutnya adalah uji hipotesis. Uji Hipotesis pada penelitian ini dilakukan dalam 2 (dua) pengujian, yaitu:

1) Uji t dan Uji F

Uji t dilakukan untuk menentukan apakah variable-variabel independen secara parsial berhubungan terhadap variable dependennya. Adapun hasilnya terlihat pada table 8 berikut.

Tabel 8

Hasil Uji t

\begin{tabular}{cccc}
\hline Variabel & $\begin{array}{c}\text { Koefisien } \\
\text { Regresi } \\
(\mathbf{B})\end{array}$ & t hitung & Sig \\
\hline Promosi & 0,156 & 2,138 & 0,035 \\
\hline $\begin{array}{l}\text { Kualitas } \\
\text { layanan }\end{array}$ & 0,339 & 1,619 & 0,109 \\
\hline Konstantina & 31,725 & 6,910 & 0,000 \\
\hline \multicolumn{3}{c}{ Fhit $=4,609$} \\
\hline \multicolumn{3}{c}{ Sumber: Data diolah } \\
\hline
\end{tabular}


Hasil penelitian menunjukan nilai t hitung pada variabel promosi sebesar 2,138 dengan nilai sig sebesar 0,002. Kriteria keputusan tolak Ho jika t hitung $>\mathrm{t}$ tabel atau sig < taraf kesalahan. Dari hasil penelitian dapat diketahui $\mathrm{t}$ hitung $=2,138$ yang artinya lebih besar dari t tabel $=2,0281$ atau sig $=0,000<$ taraf kesalahan 5\% maka dapat disimpulkan bahwa promosi yang digunakan dalam bentuk iklan berpengaruh positif terhadap keputusan mahasiswa memilih program. Hal ini ditunjukkan dari nilai koefisien regresi yang dihasilkan bertanda positif yaitu sebesar 0,156.

Hasil penelitian menunjukan bahwa nilai $t$ hitung variabel kualitas layanan sebesar 1,619 dengan nilai sig sebesar 0,000. Kriteria keputusan tolak Ho jika t hitung > t tabel atau sig < taraf kesalahan, maka dari hasil penelitian dapat diketahui t hitung $=1,619$ yang lebih kecil dari nilai t tabel sebesar 2,081. Maka dapat disimpulkan bahwa kualitas layanan tidak berpengaruh terhadap keputusan mahasiswa pada taraf kesalahan $5 \%$.

Promosi dan kualitas layanan secara bersama-sama berpengaruh terhadap keputusan mahasiswa memilih UniSadhuGuna UNIPREP BSD. Hal ini dapat dilihat dari nilai $F$ hitung sebesar 4,609 dengan nilai sig $=0,012$. Sedangkan nilai $\mathrm{F}$ table sebesar 3,505 pada tingkat kesalahan 5\%. Sehingga dapat disimpulkan bahwa terdapat pengaruh secara simultan antara promosi dan kualitas layanan terhadap keputusan mahasiswa memilih UNIPREP BSD.

2) Koefisien Determinasi

Hasil penelitian menunjukan nilai R2 sebesar 0.540, artinya bahwa variable promosi dan variable kualitas layanan secara bersama-sama mampu menjelaskan variabel keputusan mahasiswa sebesar 54\% dan $46 \%$ adalah hal lain yang tidak menjadi bagian penelitian ini.

3) Analisis dan Persamaan Regresi Linear Berganda

Dari Tabel 8, didapat persamaan regresi linear berganda sebagai berikut:

$\mathrm{Y}=31,725+0,156 \mathrm{X} 1+0,339 \mathrm{X} 2$

Dimana:

$\mathrm{X} 1 \quad$ : Promosi

X2 : Kualitas Layanan

Y : Keputusan Mahasiswa

Dapat dijelaskan sebagai berikut:

Nilai konstanta (koefisien intersep) sebesar 31,725 menyatakan bahwa jika variabel Promosi (X1) dan variabel Kualitas Layanan (X2) tetap (nol) maka nilai variabel Keputusan Mahasiswa (Y) adalah sebesar 31,725. Hasil analisis diatas dapat diartikan bahwa apabila promosi yang dilakukan semakin meningkat atau gencar maka keputusan mahasiswa memilih UNIPREP akan semakin tinggi. Hasil penelitian ini relevan dengan penelitian yang dilakukan oleh (Yulizar \& Prihatini, 2017) yang menyatakan bahwa variabel promosi berpengaruh positif terhadap keputusan pembelian. Dalam penelitian ini juga 
didukung oleh pendapat Kotler dan Amstrong yang menyatakan bahwa promosi adalah kegiatan yang mengkomunikasikan keunggulan produk dan membujuk (persuading) para pembeli untuk bersedia membeli produk tersebut (Leavy, 2014).

Promosi pada hakekatnya adalah suatu komunikasi pemasaran, artinya aktifitas pemasaran yang berusaha menyebarkan informasi, mempengaruhi/membujuk, dan atau mengingatkan pasar sasaran atas perusahaan dan produknya agar bersedia menerima, membeli dan loyal pada produk yang ditawarkan perusahaan yang bersangkutan. Tujuan dari pada perusahaan melakukanpromosimenurut (Tjiptono, 2015) adalah menginformasikan (informing), mempengaruhi dan membujuk (persuading) serta mengingatkan (reminding) pelangggan tentang perusahaan dan bauran pemasarannya. Setelah konsumen mengetahui produk yang baru, diharapkan konsumen akan terpengaruh dan terbujuk sehingga beralih ke produk tersebut. Dan pada akhirnya, perusahaan hanya sekedar mengingatkan bahwa produk tersebut tetap bagus untuk dikonsumsi. Hal ini dilakukan karena banyaknya serangan yang datang dari para pesaing.

4) Nilai koefisien regresi variabel Promosi (X1) terhadap variabel Keputusan Mahasiswa (Y) adalah sebesar 0,156. Hal ini berarti jika variabel promosi (X1) naik sebesar $1 \%$, akan meningkatkan variabel Keputusan Mahasiswa (Y) sebesar 0,156, dengan asumsi variabel Kualitas Layanan (X2) dan konstanta dianggap tetap. Promosi merupakan faktor penting yang menyebabkan informasi tersebut berguna bagi penggunanya, dan informasi dikatakan berkualitas apabila tepat, relevan dan tepat waktu. Informasi yang berkualitas akan meningkatkan Keputusan Mahasiswa.

5) Faktor pertama yang mempengaruhi keputusan pembelian adalah kualitas pelayanan. Pelayanan yang baik juga merupakan kunci penting dalam kesuksesan suatu bisnis atau perusahaan. Menurut Lovelock (dalam Tjiptono, 2015) mengemukakan bahwa kualitas pelayanan merupakan tingkatan kondisi baik buruknya sajian yang diberikan oleh perusahaan jasa dalam rangka memuaskan konsumen dengan cara memberikan atau menyampaikan jasa yang melebihi harapan konsumen. Jadi penilaian konsumen terhadap kualitas pelayanan merupakan refleksi persepsi evaluatif terhadap pelayanan yang diterimanya pada waktu tertentu.

6) Nilai koefisien regresi variabel Kualitas Layanan (X2) terhadap variabel Keputusan Mahasiswa (Y) adalah sebesar 0,339 Hal ini berarti jika variabel Kualitas Layanan (X2) naik 1 satuan, maka hal tersebut akan meningkatkan variabel Keputusan Mahasiswa (Y) sebesar 0,339, dengan asumsi bahwa variabel Promosi (X1) dianggap konstan atau tidak berubah 
Pengaruh Promosi dan Kualitas Layanan Terhadap Keputusan Pembelian Mahasiswa Memilih

Program Uniprep Bumi Serpong Damai Di Tangerang Selatan

\section{Kesimpulan}

Terdapat pengaruh yang positif dan signifikan antara promosi terhadap keputusan mahasiswa memilih program UNIPREP BSD. Semakin bagus promosi yang digunakan dalam sebuah iklan maka akan meningkatkan keputusan mahasiswa memilih program UNIPREP BSD, begitu pula sebaliknya. Sedangkan kualitas layanan tidak berpengaruh terhadap keputusan mahasiswa memilih program UNIPREP BSD pada tingkat kesalahan 5\%. Secara simultan, promosi dan kualitas layanan berpengaruh terhadap keputusan mahasiswa memilih program UNIPREP BSD. 


\section{DAFTAR PUSTAKA}

Alma, Buchari. (2018). Manajemen pemasaran dan pemasaran jasa.

Arieska, Permadina Kanah, \& Herdiani, Novera. (2018). Pemilihan teknik sampling berdasarkan perhitungan efisiensi relatif. Jurnal Statistika Universitas Muhammadiyah Semarang, 6(2).

Cresswell, J. W. (2017). Research Design: Pendekatan Kualitatif, Kuantitatif, dan Mixed (Edisi Ketiga). Yogyakarta: Pustaka Belajar.

Kholik, Abdul, \& Laeli, Sobrul. (2020). Keunggulan Bersaing Berkelanjutan Sekolah Alam Berbasis Model Resource-Based View. Tadbir Muwahhid, 4(1), 73-97.

Khotler, Philip, \& Amstrong, Gary. (2018). Principles of Marketing. Edisi 15 Global Edition. Pearson.

Kotler, Philip, \& Keller, Kevin. (2021). Marketing Management (15th global edition). Pearson Education Limited.

Leavy, Brian. (2014). Strategy, organization and leadership in a new "transientadvantage" world. Strategy \& Leadership.

Lupiyoadi, Rambat, \& Hamdani, A. (2014). Manajemen Pemasaran jasa, Salemba Empat. Jakarta.

Palupi, Weike Retno. (2020). Penerapan Uji Park, Uji White Dan Uji Glejser Untuk Mendeteksi Asumsi Heteroskedastisitas Pada Kasus Kematian Ibu Di Jawa Timur. UNIVERSITAS AIRLANGGA.

Priyanto, Innike, \& Budiwiyono, Imam. (2019). Hubungan Kadar Kreatinin Dengan Formula Huge (Hematocrit, Urea, Gender) Pada Pasien Penyakit Ginjal Kronik. Media Medika Muda, 3(2).

Priyatna, Navi Muda. (2015). Analisis Pengaruh Kualitas Layanan, Orientasi Pasar, dan Kepuasan Konsumen Terhadap Kinerja Pemasaran PT. Wisang Utama Mandiri Surabaya. Untag 1945 Surabaya.

Saputri, Oviek Dewi, \& YUYETTA, Etna Nur Afri. (2012). Analisis Faktor-Faktor yang mempengaruhi Audit Delay (studi empiris pada perusahaan-perusahaan yang terdaftar di Bursa Efek Indonesia). Fakultas Ekonomika dan Bisnis.

Sondakh, Conny. (2015). Kualitas Layanan, Citra Merek Dan Pengaruhnya Terhadap Kepuasan Nasabah Dan Loyalitas Nasabah Tabungan (Studi Pada Nasabah Taplus BNI Cabang Manado). Jurnal Riset Bisnis Dan Manajemen, 3(1).

Sugiyono. (2016). Metode Penelitian Pendidikan. Bandung: Alfabeta CV.

Tjiptono, Fandy. (2015). Kewirausahaan, Kinerja Keuangan, Dan Kelanggengan Bisnis. Jurnal Manajemen Indonesia, 15(1), 17-26.

Yulizar, Ahmad, \& Prihatini, Apriatni Endang. (2017). Pengaruh Harga dan Promosi terhadap Keputusan Pembelian Laptop Merek Acer (Studi Kasus pada Mahasiswa Fisip Undip Semarang). Jurnal Ilmu Administrasi Bisnis, 6(2), 88-97. 